\title{
Ontogeny of a sexually selected structure in an extant archosaur Gavialis gangeticus (Pseudosuchia: Crocodylia) with implications for sexual dimorphism in dinosaurs
}

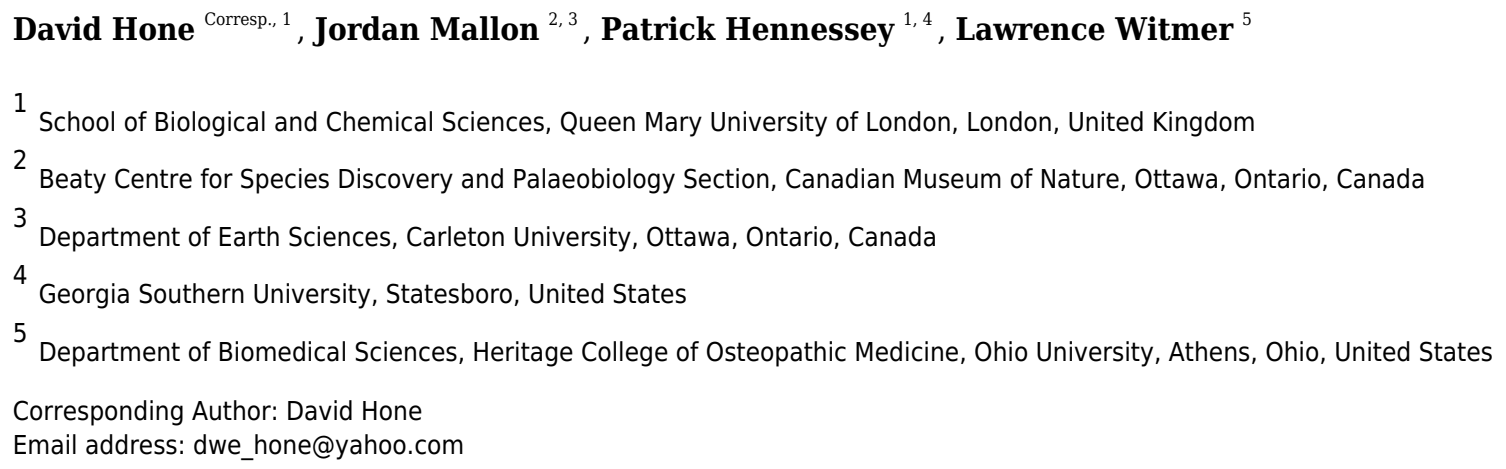

Despite strong evidence for sexual selection in various display traits and other exaggerated structures in large extinct reptiles, such as dinosaurs, detecting sexual dimorphism in them remains difficult. Their relatively small sample sizes, long growth periods, and difficulties distinguishing the sexes of fossil specimens mean that there are little compelling data on dimorphism in these animals. The extant gharial (Gavialis gangeticus) is a large and endangered crocodylian that is sexually dimorphic in size, but males also possesses a sexually selected structure, the ghara, which has an osteological correlate in the presence of a fossa associated with the nares. This makes the species a unique model for potentially assessing dimorphism in fossil lineages, such as dinosaurs and pterosaurs, as it is a large, slowly growing, egg-laying archosaur. Here we assess the dimorphism of $G$. gangeticus across 106 specimens and show that the presence of a narial fossa diagnose adult male gharials. Males are larger than females, but the level of size dimorphism, and that of other cranial features, is low and difficult to detect without a priori knowledge of the sexes, even with this large dataset. By extension, dimorphism in extinct reptiles is very difficult to detect in the absence of sex specific characters, such as the narial fossa. 


\section{Ontogeny of a sexually selected structure in an extant archosaur Gavialis}

\section{2 gangeticus (Pseudosuchia: Crocodylia) with implications for sexual}

\section{3 dimorphism in dinosaurs}

David W. E. Hone ${ }^{1}$, Jordan C. Mallon ${ }^{2,3}$, Patrick J. Hennessey ${ }^{1,4}$, Lawrence M. Witmer ${ }^{5}$

1. School of Biological and Chemical Sciences, Queen Mary University of London, Mile End Road, London, E1 4NS, UK.

2. Beaty Centre for Species Discovery and Palaeobiology Section, Canadian Museum of Nature, PO Box 3443, Station D, Ottawa, Ontario K1P 6P4, Canada.

3. Department of Earth Sciences, Carleton University, 2115 Herzberg Laboratories, 1125 Colonel By Drive, Ottawa, Ontario K1S 5B6, Canada.

4. Georgia Southern University, 4324 Old Register Rd, PO Box 8042-1, Statesboro, GA, 30460, USA.

5. Department of Biomedical Sciences, Heritage College of Osteopathic Medicine, Ohio Center for Ecology and Evolutionary Studies, Ohio University, Athens, OH 45701, USA.

Corresponding Author:

David W. E Hone

School of Biological and Chemical Sciences, Queen Mary University of London, Mile End

Road, London, E1 4NS, UK Email address: d.hone@qmul.ac.uk 
23

24

25

26

27

28

29

30

31

\section{Abstract}

Despite strong evidence for sexual selection in various display traits and other exaggerated structures in large extinct reptiles, such as dinosaurs, detecting sexual dimorphism in them remains difficult. Their relatively small sample sizes, long growth periods, and difficulties distinguishing the sexes of fossil specimens mean that there are little compelling data on dimorphism in these animals. The extant gharial (Gavialis gangeticus) is a large and endangered crocodylian that is sexually dimorphic in size, but males also possesses a sexually selected structure, the ghara, which has an osteological correlate in the presence of a fossa associated with the nares. This makes the species a unique model for potentially assessing dimorphism in fossil lineages, such as dinosaurs and pterosaurs, as it is a large, slowly growing, early maturing, egglaying archosaur. Here we assess the dimorphism of G. gangeticus across 106 specimens and show that the presence of a narial fossa diagnose adult male gharials. Males are larger than females, but the level of size dimorphism, and that of other cranial features, is low and difficult to detect without a priori knowledge of the sexes, even with this large dataset. By extension, dimorphism in extinct reptiles is very difficult to detect in the absence of sex specific characters, such as the narial fossa.

\section{Introduction}

Sexual selection is a major evolutionary driver of many biological traits in animals, and is important for understanding the anatomy, behavior, and evolution of species and clades. One major indicator of sexual selection is sexual dimorphism where one sex is larger than the other and / or shows some form of exaggerated structure absent in the other, indicating an investment 
49 in resources as a means of increasing reproductive success. However, assessing sexual selection

50 in extinct lineages is very difficult in groups such as the non-avian dinosaurs (hereafter simply

51 'dinosaurs') and other reptiles (Knell et al., 2013), and attempts in the past to identify sexual

52 dimorphism in dinosaurs have had no real success (see Mallon, 2017 for a recent review).

Lineages may show only sexual size dimorphism, or dimorphism of major osteological traits

54

55

56

57

(e.g., crests and horns), or may be under mutual sexual selection leading to reduced or even absent dimorphism. Further, dimorphic traits are not necessarily linked to evolutionary pressures based around reproductive success or socio-sexual dominance (e.g., see Hone, Naish \& Cuthill, 2012; Hone \& Mallon, 2017; and references therein). As a result, the case for sexual selection in dinosaurs and other extinct reptile lineages has been controversial. In some taxa, however, there is evidence for sexual dimorphism (e.g., Shringasaurus Sengupta, Ezcurra \& Bandyopadhyay, 2017) and for the presence of traits that were likely used as socio-sexual signals (O'Brien et al., 2018). Even so, the detection of sexual dimorphism is an important component of understanding sexual selection, and the current lack of evidence for dimorphism in dinosaurs (e.g., Hone, Naish \& Cuthill, 2012; Mallon, 2017 and references therein) remains at least a curious anomaly.

There are also limitations to the available models among extant animals for comparison to extinct animals such as dinosaurs. Large mammals may be comparable in size and have some ecological similarities to dinosaurs, but there are major differences in evolutionary histories and growth trajectories. Extant reptiles often show high levels of sexual size dimorphism (Fitch, 1981; Cox, Butler \& John-Adler, 2007) but most reptiles are small and attain adult size rapidly. The extant phylogenetic bracket for dinosaurs consists of birds and crocodylians, making these two groups potentially better candidates (Witmer, 1995a). However, as with mammals, birds mature rapidly, and their small size and often limited skeletal trait dimorphism also makes them 
72 problematic. Crocodylians, in contrast, may be an excellent model with respect to dimorphism.

73 As with many or even most dinosaurs, they reach large sizes, grow slowly over many years, are

74 sexually mature well before maximum size, lay eggs, and have large numbers of offspring.

75 Importantly, at least some show sexual dimorphism in body size (Caiman - Thorbjarnarson,

76 1994; Alligator - Wilkinson \& Rhodes, 1997; Crocodylus - Platt et al., 2009).

77 Among extant crocodylians, the gharial (Gavialis gangeticus) is a uniquely appropriate example (Fig. 1). Gharials are specialised piscivores having an unusually long and slender snout (Whitaker \& Basu, 1983). Now known in the wild only from India, Bangladesh, and Nepal, this species is critically endangered, with the already small wild populations having suffered significant losses in recent decades (Hasan \& Alam, 2016; Lang, Chowfin \& Ross, 2019). They are among the largest of the extant crocodylians, with the largest recorded animal (a male) reaching $6.25 \mathrm{~m}$ in total length and weighting $977 \mathrm{~kg}$, although more typical adults are $3.5-4.5 \mathrm{~m}$ long, with males being larger than females (Hasan \& Alam, 2016).

Gharials show sexual dimorphism not just in body size, but also in their cranial anatomy. Larger males bear a ghara - a growth on the rostrum that is absent in females (Martin \& Bellairs, 1977; Biswas, Acharjyo \& Mohapatra, 1977; Whitaker and Whitaker, 1989). The ghara is a softtissue structure that grows behind and over the external nares, and is supported by a depression on the bony rostrum, anterior to the nares (Iordansky, 1973), in the larger male skulls (Martin \& Bellairs, 1977). Some early descriptions of the ghara suggest that it is bony and may even be inflated, but this is not the case (Martin \& Bellairs, 1977). sexually mature males (Martin \& Bellairs, 1977; Biswas, Acharjyo \& Mohapatra, 1978;

Whitaker \& Whitaker, 1989), it would be reasonable to assume that it functions in sexual 
95

96

97

display. Large males are seen to be dominant over smaller males and females (Whitaker \& Basu, 1983). Suggested functions of the ghara include altering the calls of males (a hissing sound not made by females or young males; Whitaker \& Whitaker, 1989), or as a visual display signal to females (Martin \& Bellairs, 1977). Large males also possess an additional secondary sexual characteristic consisting of a pair of expanded bony bullae on the dorsal aspect of the pterygoid bones (Fig. 2) as also seen in other crocodylians (e.g., Alligator - Fig. 3). In gharials, the bullae are not present in small males or apparently in females (though this is uncertain). The egg-shaped bullae are dorsal dilations of the bony nasopharyngeal duct (Wegner, 1958; Witmer, 1995b, 1999). Although the resonant properties of the pterygoid bullae have yet to be demonstrated experimentally, they would function as vocal resonating chambers as an inescapable bioacoustic or biophysical consequence of their connection to the vocal tract. Thus, bullae may be linked to the ghara functioning in sound production or modification (Martin \& Bellairs, 1977). However, vocalisations are rare (Whitaker \& Basu, 1983), potentially arguing against this interpretation.

Ontogenetic data are limited to a few scattered accounts. For example, Biswas, Acharjyo \& Mohapatra (1978) describe a male of c. $2.5 \mathrm{~m}$ total length, and aged 11.5 years, as showing the first signs of a ghara. The same animal was described as showing 'sex play' (which we assume to mean courtship behaviour), aged 12.5 years, suggesting that the growth of the ghara is linked to maturity (females appear to mature at around $2.6 \mathrm{~m}$ in length; Whitaker \& Basu, 1983).

Similarly, Whitaker and Whitaker (1989) described one male as having a snout resembling that of a female until it was 11 years old, when the ghara started to develop; the ghara folded caudally over the nostrils at age 14 years, and reached fully adult form by age 18 years. Martin and Bellairs (1977) suggested that males around $3 \mathrm{~m}$ long will exhibit a small ghara, though they also referred to previous reports suggesting that this is normally present only in males in excess of 4.5 
$118 \mathrm{~m}$ long. Clearly, however, this is a feature that is not present in small / young animals. Moore et

119 al. (2019) observed that onset of puberty in male Morelet's crocodiles (Crocodylus moreletii),

120 measured by the development of the penile glans, was coincident with changing cranial shape,

121 suggesting a potentially similar pattern.

122 Here we look at sexual dimorphism in the skull of Gavialis as a model for detecting sexual

123 dimorphism and the identity of specimens in extinct reptiles, including dinosaurs. We use the

124 largest known sample of gharial data to assess sexual dimorphism in these animals and to

125 examine the feasibility of detecting dimorphism in extinct reptile lineages. This is done by

126 examining the relative growth (allometry) of changes in various measurements and features of

127 the skull, including the fossa and pterygoid bullae, and searching for evidence of bimodality

128 among adult individuals.

129

130

131

132

133

134

135

136

137

138

139

140

141

142

\section{Abbreviations}

BSL, basal skull length (premaxilla to occipital condyle); IW, interorbital width; MW, maximum width of skull (across quadratojugals); MWAO, maximum width across orbits; NFML, narial fossa maximum length; NFMW, narial fossa maximum width; NML, naris maximum length; NMW, naris maximum width; OCW, occipital condyle width; PBL, average pterygoid bulla length; PEMW, premaxillary expansion maximum width; SL_RTO, snout length rostral to orbits; SMW, snout minimum width (mid-length).

\section{Materials \& Methods}

Two binary variables and 13 continuous variables (Fig. 4; Appendix 1) were collected from 106 gharial skulls accessioned in 36 museum collections around the world. Where possible, these 
143 were measured first-hand with callipers, but it was necessary to measure most of them digitally

144 based on photographs including scale bars. It was impossible to measure all variables because

145 some skulls were incomplete or variably covered with skin. Sex data were not given for any

146 specimens. We therefore assumed that specimens bearing a narial fossa (the osteological

147 correlate of the ghara) were male; those lacking a narial fossa were assumed to be immature

148 and/or female. The narial fossa (Figs. 1, 2, 4) is the depression in the premaxillary bones adjacent

149 to the bony nasal aperture (i.e., the opening into the nasal passage). A small ghara has been

150 reported in a captive animal that, when dissected, was seen to have ovaries, but this was assumed

151 to have been a pathological individual (Martin \& Bellairs, 1977). It is therefore reasonable to

152 assume that animals with a narial fossa are male, and hereafter all mentions of male specimens

153 are based on this assumption.

To assess allometry in those continuous variables, it was necessary to first choose a

155

156

157

158

159

160

161

162

163

164

165

regressor. Visual inspection of the skulls, and prior published work (Piras et al., 2014), suggested

that variables associated with the snout vary widely in the adults, so we chose maximum skull

width (MW), measured across the outside of the quadratojugals, as our regressor, which is

consistent with the recommendations of O'Brien et al. (2019). The data were initially log-

transformed then subjected to reduced major axis (RMA) regression, which accounts for

measurement error in both the independent and dependent variables. Isometry was rejected if the

confidence intervals of the regression slope did not bound a value of 1 . Negative allometry was

manifest if the confidence intervals were $<1$; positive allometry was manifest if the confidence

intervals were $>1$.

We used the gharial data to attempt to model the detection of sexual dimorphism in the fossil record by disregarding sex information (inferred from narial fossa presence/absence). As 
166 advocated by Mallon (2017), we tested for dimorphism in the continuous data by first subjecting

167 the residuals of the RMA regressions to Shapiro-Wilk and Anderson-Darling tests for normality

$168(\alpha=0.05)$. Residuals were then subjected to a supplemental Hartigan's dip test, which yields the

169 likelihood that the data are distributed unimodally (Hartigan \& Hartigan 1985). Residuals were

170 also subjected to mixture analysis, a maximum-likelihood procedure used to estimate univariate

171 parameters (e.g., mean, standard deviation) of two or more univariate normal distributions from a

172 pooled sample. The fit of the models was assessed using the Akaike Information Criterion (AIC).

173 As a final attempt to quantify sexual dimorphism, we reasoned that dimorphic structures

174 should exhibit higher variance of the RMA residuals than non-dimorphic structures. To test for

175 this, we used Levine's test for homogeneity of variance from means, with follow-up F-test

176 pairwise comparisons. The multiple comparisons were adjusted using Holm-Šidák correction.

\section{Results}

179 General observations

Maximum skull width (MW) ranges between $13 \mathrm{~mm}$ and $356 \mathrm{~mm}$ (embryonic and large adult $\mathrm{mm}$, and total estimated lengths of the animals between $17 \mathrm{~cm}$ and $5.9 \mathrm{~m}$ (see Appendix 1). More than 30 of our specimens represent animals of estimated total length in excess of $5 \mathrm{~m}$, showing that this dataset is biased towards larger animals, presumably at least in part as a result of selective acquisition of large specimens for museums. The smallest skull having a narial fossa is the Madras Crocodile Bank Trust male, where $\mathrm{MW}=217 \mathrm{~mm}$ and BSL $=581 \mathrm{~mm}$ (Fig. 5) or approximately $60 \%$ maximum size. Above MW $=280 \mathrm{~mm}$ (BSL c. $715 \mathrm{~mm}$ ), all skulls possess a narial fossa; thus, the largest skulls are male. The smallest skull possessing pterygoid bullae (but 
189 lacking a narial fossa) is from the American Museum of Natural History (AMNH) 110145 ,

190 where $\mathrm{MW}=179 \mathrm{~mm}(\mathrm{BSL}=459 \mathrm{~mm})$.

191 Thirty-one of the 106 skulls possess narial fossae. Where determinable (some lack palates or 192 are otherwise obscured), all of these possess pterygoid bullae, indicating that they are

193 predominantly, if not universally, present in males. There are, however, 11 skulls lacking a narial 194 fossa but having bullae (Fig. 5). Of these, six are smaller than the unnumbered Madras Crocodile 195 Bank Trust male, and all are smaller than $\mathrm{MW}=280 \mathrm{~mm}(\mathrm{BSL}=743 \mathrm{~mm})$, which is the lower 196 threshold at which the narial fossa is consistently expressed (Fig. 5). If having a pterygoid bulla 197 is indicative of the male sex, which seems likely, it shows up earlier in ontogeny, at 198 approximately 50\% maximum size, than does the narial fossa.

\section{Allometry}

The results for the all-inclusive allometric analyses are summarized in Figure 6 and Table

$\mathrm{S} 1 . \mathrm{MW}$ is a good predictor of all continuous cranial variables $\left(\mathrm{R}^{2}>0.92, p<0.0001\right)$. Positively allometric variables include PEMW (premaxillary expansion maximum width) and IW (interorbital width). Negatively allometric variables include BSL (basal skull length), OCW (occipital condyle width), NML (naris maximum length), and MWAO (maximum width across orbits). The three remaining variables_-SL_RTO (snout length rostral to orbits), SMW (snout minimum width), and NMW (naris maximum width)—grow isometrically. PEMW, and NMW (Fig. 6), suggesting that these variables increase very rapidly at large body

210 sizes. Follow-up allometric analyses of just the male data (having pterygoid bullae and narial 
211 fossae) reveal positive allometry in all three variables (Table S2), with slopes greater than those

212 reported for the entire dataset, albeit with slightly reduced goodness of fit $\left(\mathrm{R}^{2}>0.75, p<\right.$

$2130.0001)$.

214 NFML and NFMW (narial fossa maximum length and width, respectively) scale with positive 215 allometry, but the relationship with MW is insignificant (Table S2). PBL (average pterygoid 216 bulla length) is weakly but positively correlated with skull size in males. We were unable to 217 reject the null hypothesis of isometry (Table S2).

\section{Sexual dimorphism}

Presumed males categorically differ from females in the presence of a narial fossa $(\sim$ ghara $)$ and, ostensibly, the presence of pterygoid bullae. Males are further distinguished by their absolutely larger skulls at maturity (MW $>287 \mathrm{~mm}, \mathrm{BSL}>715 \mathrm{~mm})$, relatively shorter and wider rostra, and wider terminal rosettes that support larger nares.

Without knowing the sexes a priori (as in fossil taxa), it is otherwise difficult to detect dimorphism in those continuous variables. With the exception of NML, the residuals for all cranial variables are significantly non-normal, but in no case are they significantly non-unimodal

227 (Table S3). Mixture analysis shows that pooled BSL values are best modelled by two normal distributions, but further investigation shows that these distributions distinguish between juvenile and more mature individuals, not sexual dimorphs (Group 1 mean $=-0.205 \pm 0.0739$, Group 2 mean $=0.00617 \pm 0.0312$ ). The ability to detect dimorphism in the three most obviously dimorphic continuous variables (SMW, PEMW, and NMW) does not increase by considering only adults (MW $\geq 179 \mathrm{~mm}, \mathrm{BSL} \geq 459 \mathrm{~mm}$ the smallest presumed male having pterygoid 
233 bullae). The adult NMW residuals are not significantly non-normal, and none of the residuals are

234 either significantly non-unimodal or best fit by two normal distributions (Table S3).

235 On average, the SMW, PEMW, and NMW residuals exhibit higher variances $(\geq 0.004)$ than

236 the non-dimorphic residuals (Fig. 7). Levene's test for homogeneity of variance from means is

237 highly significant $(\mathrm{p}<0.0001)$. Follow-up pairwise comparisons (Table S4) reveal that variance

238 for the SMW, PEMW, and NMW residuals is usually significantly higher compared to the other

239 residuals. Variance does not differ significantly between any of the three dimorphic variables.

240

241

242

243

244

245

246

247

248

249

250

251

252

253

254

255

\section{Discussion}

\section{Sexual dimorphism and sexual selection in Gavialis}

The results here broadly align with previous assessments of dimorphism and the ghara in G. gangeticus. Males are larger than females, and the former show both a fossa associated with the nares and bullae on the palate. These latter features appear only in larger animals, and thus with the onset of sexual maturity. The smallest specimen with a narial fossa in our sample is slightly smaller, at $581 \mathrm{~mm}$ in basal skull length $(\mathrm{MW}=217 \mathrm{~mm})$, than the smallest reported by Martin and Bellairs (1977; $69 \mathrm{~cm})$, but the samples are broadly comparable. There are several large animals (with BSL $>700 \mathrm{~mm}, \mathrm{MW}>270 \mathrm{~mm}$ ) that lack a fossa, and these would be considered females, though they would be unusually large with body sizes over $4.5 \mathrm{~m}$.

Martin and Bellairs (1977) stated that a ghara appears in males of around $3 \mathrm{~m}$ in total length, which, following their head to body ratio of 1:6, would equate to a basal skull length of approximately $42 \mathrm{~cm}$. This is considerably smaller than the smallest skull with a narial fossa recorded here. We infer from this finding that the ghara may be growing for some time before the ghara's soft tissues are extensive enough to generate the bony fossa that supports it (just as 
256 muscle scars tend to be subtle in small animals and more prominent in large animals). This

257 would match with the apparent development of the bullae prior to the presence of the fossa and

258 would indicate that the ghara and bulla develop nearly simultaneously. Above a BSL of $680 \mathrm{~mm}$

259 (MW > $240 \mathrm{~mm})$, there are 23 specimens where the presence of a fossa and bullae can be

260 reliably determined (see Appendix 1). Of these, 20 possess both, two possess neither, but one

261 specimen (Royal Scottish Museum RSM 1948.58.1) has bullae and no fossa. Thus there is not a

262 perfect 1:1 ratio between larger animals possessing both a fossa and bullae or neither, though

263 clearly a strong majority do fall into this category. We therefore provisionally consider the bullae

264 to be a feature of adult male animals, but recognise that this may not be exclusive.

265 The narial fossa shows strong positive allometry compared to other traits in the skull (Fig.

266 6), which would suggest that the affixed ghara functions as a sexually selected display feature

267 (cf. O'Brien et al., 2018). This also fits with the observation of Dinets (2013) that males have a

268 sex-specific head-up posture on land, which elevates the ghara. The ghara would also be a major

269 handicap to males when hunting, and thus would form an honest signal of the fitness of the

270 owner. The large size of the ghara (Fig. 1) might also increase visibility to prey, and would

271 certainly offer considerable drag on the otherwise thin snout of an animal hunting in water

272 (Martin \& Bellairs, 1977), presumably incurring a cost to feeding effectiveness. This is

273 especially true since an extra drag generated near the tip of the jaws would be much greater than

274 closer to the rear of the skull, as drag is a function of distance from the joint squared. The

275 extreme variation of the morphology of the ghara (Fig. 1) also points to it being a socio-sexual

276 signal (see Hone \& Naish, 2013 and references therein) that would be under selection.

277 Initially the pterygoid bullae must grow rapidly as the smallest record of them in our sample

278 is still sizeable $(37 \mathrm{~mm}$ long on the Field Museum of Natural History $(\mathrm{FMNH}) 22025, \mathrm{BSL}=$ 
$279611 \mathrm{~mm}, \mathrm{MW}=218 \mathrm{~mm}$ ), although it is possible that at smaller sizes they are hidden in

280 photographs of the palate. However, bullae growth is isometric, which suggests that although

281 they are important structures, their size is not critical. We hypothesise, therefore, that these

282 features function as an acoustic signal to females (or perhaps other males) that the male is

283 mature, but that there is no additional information about the size and quality of the male

284 possessing them or otherwise their growth would be expected to be positively allometric.

Although it has been noted that gharials rarely produce calls, they are known to vocalise (Whitaker \& Basu, 1983), including ‘buzzing’ during courtship (Dinets, 2013). Many crocodylians communicate using very low-frequency vocalizations (Garrick, Lang \& Herzog, 1978), some of which extend into the infrasonic range (i.e., below the range of normal human hearing; Todd, 2007). Although gharials are unusual among the larger crocodylians, in that they are not known to produce infrasonic calls (Dinets, 2013), these or other vocalisations may not have been detected by previous researchers. The bullae are connected to the vocal/respiratory tract and would act as acoustic resonators, potentially lowering the frequencies of sounds produced. Whether the pterygoid bullae are important for acoustic signalling remains unconfirmed. They are, however, large structures that we presume have some positive function, in that they occupy space in the orbit and palatal regions, and would presumably adversely affect other functions (e.g., the bullae expand into the adductor chamber and hence decrease the available space for jaw adductor muscles such as M. pterygoideus dorsalis). They appear in 298 larger, mature males, and infrasonic calls of other crocodylians are produced only by males (Dinets, 2013). The vocal capabilities of alligators are well known (Garrick, Lang \& Herzog, 1978; Vliet, 1989; Todd, 2007), and alligators also possess inflations of the nasopharyngeal ducts 
302 presumably non-homologous), perhaps lending some credence to an acoustic resonance function

303 in gharials, as well (Fig. 3). Dinets (2013) reported specifically that gharials do not use

304 infrasound, but the basis for this assertion is not clear, and we regard acoustic signalling

305 (potentially including an emphasis on low-frequency sounds, perhaps even infrasound) as the

306 current best-supported hypothesis for the function of the pterygoid bullae.

307 When analysed in the presumed males alone, some of the traits in the skull also show

308 positive allometry. The premaxillary expansion maximum width (PEMW), the snout minimum

309 width (SMW), and the naris maximum width (NMW) are all disproportionately larger in the

310 largest males (Fig. 7). All are potentially associated with the ghara and the size increase of the

311 fossa to which it attaches. We suggest here that the expansion of the premaxillary rosette and

312 relative increase of the snout minimum width could help strengthen the skull given the drag of a

313 large ghara, but could also potentially have an ecological function permitting engaging of larger 314 prey.

Given that the pterygoid bullae ontogenetically appear in presumed males that would be of

316

317

318

319

320

321

322

323

breeding age, we suggest that they provide a general infrasonic acoustic signal that would

function to advertise their maturity to females (and also perhaps to other males). This signal would serve to attract attention to the male (even while out of line of sight such as underwater), and the primary visual signal of status and quality would be the ghara. The visual signal is enhanced by a spray of water emerging from the ghara itself upon exhalation, accompanied by an audible hiss and hum (Whitaker \& Whitaker, 1989).

\section{Detecting sexual dimorphism in the fossil record}


To date, no dinosaur has been determined to exhibit sexual dimorphism under rigorous

325

326

327

328

329

330

331

332

333

334

335

336

337

338

339

340

341

342

343

344

345

346

analysis (Mallon, 2017). Tests for dimorphism in fossil taxa may be confounded by a

combination of small sample sizes and protracted growth, coupled with uncertainty of the age or sex of most specimens. These conspire to ensure that young individuals of the larger sex are conflated with older individuals of the smaller sex (Hone \& Mallon, 2017). Dinosaurs matured sexually before they reached growth asymptotes (e.g., Erickson et al., 2007; Lee \& Werning, 2008), and as a result may be expected to have initiated the growth of a sexually selected structure earlier in ontogeny than in animals where they reach maximum size at a similar time to sexual maturity. This also fits with the high juvenile mortality of dinosaurs, and thus may have promoted early reproduction (Hone \& Mallon, 2017). Thus, although we may expect to, and do, see strong positive allometry for features such as crests and horns under sexual selection (Hone, Wood \& Knell, 2016; Brown, 2017), these features may start earlier and grow more slowly than in traditional models, such as large mammals.

Our results support these general contentions that dimorphism is very difficult to detect in taxa showing growth over considerable periods of time. Were these animals recovered from the fossil record, the presence of the fossa and bullae give clear osteological characters that are not obviously functional (sensu Hone, Naish \& Cuthill, 2012) and appear only in larger specimens, and these would likely be regarded as indicative of sex. Gavialis gangeticus is identified by numerous osteological traits (Iordansky, 1973) present in all specimens that would signify all specimens as belonging to a single species. However, in the absence of these discrete traits, determining dimorphism would be very difficult. Hone and Mallon (2017) assessed detection of sexual dimorphism in alligators based on body size, and suggested a minimum of 60 animals might be needed to statistically support dimorphism, even when the difference between sexes 
347 was strong and could be measured effectively. Here in the gharials, there is no clear statistical

348 signal for any continuous traits producing two clusters across all specimens, despite a dataset of

349 over 100 specimens. Even when our approach is restricted to osteological mature individuals, the

350 signal is weak and arguably present only in some features that are also associated with the ghara.

351 Were these fossilized gharial specimens, and having no a priori knowledge of their dimorphism,

352 there would be little to separate out the sexes.

There few datasets in the fossil record for dinosaurs in excess of even 50 specimens where

354

355

356

357

traits such as size and potentially dimorphic display features can be reliably measured. The sample sizes and levels of specimen completeness in most assemblages are low enough that dimorphism will be hard to detect unless there are clear presence/absence traits or very different morphologies between sexes. This is not say that sexual dimorphism was not present in dinosaurs - and more detailed analyses of assemblages with large samples and completeness (e.g., Coelophysis; Griffin, 2018) are merited—only that it is difficult to demonstrate quantitatively.

\section{Future work and conservation implications}

Further work is needed to confirm the hypotheses laid out here. An exact relationship between the timing of sexual maturity and the physical expression of the ghara, narial fossa, and pterygoid bullae is key to understanding gharial reproductive biology. A formal assessment of any social or mating displays, and the differing acoustic and visual components of this, are also important and may provide information critical to breeding efforts given the severe extinction risk of this species (Lang, Chowfin \& Ross, 2019). 
This study also raises additional issues regarding the functional morphology of gharials,

370 which may also be important for understanding their ecology and behaviour. The ghara will

371 induce severe drag on the jaws during prey apprehension underwater, while the bullae will affect

372 the palatal muscles, which will influence the functioning of the jaws.

Finally, we note that the largest narial fossae are associated with an increase in the size of

374 the terminal rosette and a broadening of the snout (increased minimum width), and this may increase the ability of males to catch larger prey. Although we did not measure tooth size across

376 all specimens, we note that some of the largest males (e.g., Grant Museum - LDUCZ X215)

377 apparently have disproportionately large teeth compared to smaller animals, and this would

378 likely allow them to tackle larger prey than may be expected. Given the great differences in size

379 between osteologically mature gharials and young juveniles, there would be niche partitioning

380 between various different growth stages, as seen in other crocodylians (Dodson, 1975). However, 381 there may also be separation between larger (and presumably fitter) gharial males and other adult 382 animals, and if so, this may also be a very important consideration for sustaining populations. If

383 high-quality males are removed from a population, this has the potential for profoundly negative 384 effects in small populations (Knell \& Martínez-Ruiz, 2017). So if our hypothesis about prey 385 preference is correct, suitable prey for larger males must be a consideration in establishing 386 suitable habitats for sustainable gharial populations or they may be at risk.

Moore et al. (2019) noted an increase in size in the anterior teeth of male Morelet's crocodiles (Crocodylus moreletii) at sexual maturity and suggested that this increase was linked to male-male interactions over females. This could also be the case in gharials. However, 390 developmentally this change occurs much earlier in the crocodile than the shift suggested here, and it was only the anterior teeth that changed in the crocodile and not the entire tooth row, as we 
392 observed in Gavialis. This difference implies that these respective changes in tooth morphology

393 are not synonymous. In any case, as noted by Moore et al. (2019), increased head size is

394 correlated with increased bite power and opportunities to tackle larger prey (Erickson et al.,

395 2012). So regardless of the selective pressures that might produce more robust crania and teeth in

396 large males, the hypothesised dietary shift may still be present.

397

398

399

400

401

402

403

404

405

406

407

408

409

410

411

412

413

414

415

416

\section{Conclusions}

We agree with previous studies that the ghara and associated narial fossa, and probably the pterygoid bullae, are male traits of gharials, and most likely have a socio-sexual function in displays. Limited dimorphism in size and various cranial traits are exhibited with males being larger than females.

In the absence of key traits, determining moderate sexual dimorphism (body size or other measurements) is going to be extremely difficult, even with good sample sizes and complete sets of data. Doing so for such fossil taxa as dinosaurs (but also many other extinct reptiles and amphibians) is extraordinarily difficult unless the degrees of dimorphism are extreme. Prolonged growth, and the overlap of males and females in terms of body size and even features linked to sexually selected structures (such as the width of the terminal rosette seen here), make the sexual identity of individual specimens highly cryptic.

\section{Acknowledgements}

We thank the following colleagues and curators for access to specimens, photographs, and computed tomographic data: Victoria Arbour, Salvator Bailon, Jordan Bestwick, Dave 
417 Blackburn, Ashley Burns-Meerschaert, Mark Carnall, Jim Clark, Tannis Davidson, Emily

418 Durkin, Michael Franzen, Jennifer Gallichan, Dan Gordon, Ashely Hall, Natalie von Hoose,

419 David Kizirian, Gunter Koehler, Jeff Lang, Josh Mata, Colin McHenry, Zachary Morris, Emma-

420 Louise Nicholls, Olivier Pauwels, Stephanie Pierce, Rhian Rowson, Scott Sampson, Mark

421 Scherz, Coleman Sheehy III, Ed Stanley, Jeff Streicher, Frank Tillack, Zena Timmons, Paolo

422 Viscardi, Kent Vliet, Lauren Vonnahme, Aki Watanabe, Gregory Watkins-Colwell, May

423 Webber, Rom Whitaker, Nikhil Whitaker. We thank Peter Dodson, Michelle Stocker and Jeff

424 Lang for their comments as referees, and John Hutchinson for his editorial comments, all of

425 which helped improve earlier versions of this manuscript.

\section{ADDITIONAL INFORMATION AND DECLARATIONS}

428

Funding

429

This work was supported by National Science Foundation grants to Lawrence M. Witmer

(IBN-9601174, IOB-0343744, IOB-0517257, IOS-1050154, and IOS-1456503). The funders had

431

no role in study design, data collection and analysis, decision to publish, or preparation of the

432 manuscript.

Grant Disclosures

The following grant information was disclosed by the authors: National Science Foundation:

435

IBN-9601174, IOB-0343744, IOB-0517257, IOS-1050154, and IOS-1456503.

436

437 


\section{References}

439

440

441

442

443

444

445

446

447

448

449

450

451

452

453

454

455

456

457

458

459

Biswas S, Acharjyo, LN, Mohapatra S. 1978. A note on the protuberance or knob on the snout of the male gharial (Gavialis gangeticus (Gmelin)). Journal of the Bombay Natural History Society 74:536-537.

Brown CM. 2017. An exceptionally preserved armored dinosaur reveals the morphology and allometry of osteoderms and their horny epidermal coverings. PeerJ 5:p.e4066.

Cox RM, Butler MA, John-Alder HB. 2007. The evolution of sexual size dimorphism in reptiles. In: Fairbarin DJ, Blanckenhorn WU, Székely, eds. Sex, size and gender roles: evolutionary studies of sexual size dimorphism Oxford, Oxford University Press, 38-49.

Dinets V. 2013. Long-distance signaling in Crocodylia. Copeia 2013:517-526.

Dodson P. 1975. Functional and ecological significance of relative growth in Alligator. Journal of Zoology 175:315-355.

Erickson GM, Curry Rogers K, Varricchio DJ, Norell MA, Xu X. 2007. Growth patterns in brooding dinosaurs reveals the timing of sexual maturity in non-avian dinosaurs and genesis of the avian condition. Biology Letters 22:558-561.

Erickson GM, Gignac PM, Steppan SJ, Lappin AK, Vliet KA, Brueggen JD, Inouye BD, Kledzik D, Webb GJW. 2012. Insights into the ecology and evolutionary success of crocodilians revealed through bite-force and tooth-pressure experimentation. PLOS One 7:e31781

Fitch HS. 1981. Sexual size differences in reptiles. Miscellaneous Publications of the Museum of Natural History University of Kansas 70:1-72. 
460 Garrick LD, Lang JW, Herzog HA. 1978. Social signals of adult American alligators. Bulletin of 461 the AMNH 160:3.

462 Griffin CT. 2018. Developmental patterns and variation among early theropods. Journal of $463 \quad$ Anatomy 232:604-40.

464 Hartigan JA, Hartigan PM. 1985. The dip test of unimodality. Annals of Statistics 13:70-84.

465 Hasan K, Alam S. 2016. Gharials of Bangladesh. IUCN, International Union for Conservation of 466 Nature, Bangladesh Country Office, Dhaka, Bangladesh, 92 pp.

Hone DWE, Naish D, Cuthill IC. 2012. Does mutual sexual selection explain the evolution of head crests in pterosaurs and dinosaurs? Lethaia 45:139-156.

Hone DWE, Naish D. 2013. The 'species recognition hypothesis' does not explain the presence and evolution of exaggerated structures in non-avialan dinosaurs. Journal of Zoology 290:172-180.

Hone DWE, Wood D, Knell RJ. 2016. Positive allometry for exaggerated structures in the ceratopsian dinosaur Protoceratops andrewsi supports socio-sexual signaling. Palaeontologia Electronica 19:5A.

Hone DWE, Mallon JC. 2017. Protracted growth impedes the detection of sexual dimorphism in non-avian dinosaurs. Palaeontology 60:535-545.

Iordansky NN. 1973. The skull of the Crocodilia. In: Gans C, Parsons T, eds. Biology of the Reptilia. London, Academic Press 201-262.

Knell RJ, Naish D, Tomkins JL, Hone DW. 2013. Sexual selection in prehistoric animals: detection and implications. Trends in ecology and evolution 28:38-47. 
481 Knell RJ, Martínez-Ruiz C. 2017. Selective harvest focused on sexual signal traits can lead to 482 extinction under directional environmental change. Proceedings of the Royal Society $B$ 483 284:20171788.

484

485

486

487

488

489

490

491

492

493

494

495

496

497

498

499

500

501

Lang J, Chowfin, S \& Ross JP. 2019. Gavialis gangeticus (errata version published in 2019). The IUCN Red List of Threatened Species 2019: e.T8966A149227430.

Lee AH, Werning S. 2008 Sexual maturity in growing dinosaurs does not fit reptilian growth models. Proceed.ings of the National Academy of Sciences 105:582-7.

Mallon JC. 2017. Recognizing sexual dimorphism in the fossil record: lessons from nonavian dinosaurs. Paleobiology 43:495-507.

Martin BGH, Bellairs AA. 1977. The narial excrescence and pterygoid bulla of the gharial, Gavialis gangeticus (Crocodilia). Journal of Zoology 182:541-558.

Moore BC, Holliday CM, McMurry ST, Platt SG, Rainwater TR. 2019. Correlation between increased postpubertal phallic growth and the initiation of cranial sexual dimorphisms in male Morelet's crocodile. Journal of Experimental Zoology Part A: Ecological and Integrative Physiology.

O’Brien DM, Allen CE, Van Kleeck MJ, Hone DWE, Knell RJ, Knapp A, Christiansen S, Emlen DJ. 2018. On the evolution of extreme structures: static scaling and the function of sexually selected signals. Animal Behaviour 144:95-108.

O’Brien HD, Lynch LM, Vliet KA, Brueggen J, Erickson GM, Gignac PM. 2019. Crocodylian head width allometry and phylogenetic prediction of body size in extinct crocodyliforms. Integrative Organismal Biology 1:006. 
502 Piras P, Buscalioni AD, Teresi L, Raia P, Sansalone G, Kotsakis T, Cubo J. 2014. Morphological $503 \quad$ integration and functional modularity in the crocodilian skull. Integrative zoology 9:498504516.

505 Platt SG, Rainwater TR, Thorbjarnarson JB, Finger AG, Anderson TA, McMurry ST. 2009. Size 506 estimation, morphometrics, sex ratio, sexual size dimorphism, and biomass of Morelet's 507 crocodile in northern Belize. Caribbean Journal of Science 45:80-94.

508 509

Sengupta S, Ezcurra MD, Bandyopadhyay S. 2017. A new horned and long-necked herbivorous stem-archosaur from the Middle Triassic of India. Scientific reports 7:8366.

Thorbjarnarson JB. 1994. Reproductive ecology of the spectacled caiman (Caiman crocodilus) in the Venezuelan Llanos. Copeia 1994:907-919.

Todd NPM. 2007. Estimated source intensity and active space of the American alligator (Alligator mississippiensis) vocal display. Journal of the Acoustical Society of America 122:2906-2915.

Vliet KA. 1989. Social displays of the American alligator (Alligator mississippiensis). American Zoologist 29:1019-1031.

Wegner RN. 1958. Die Nebenhöhlen der Nase bei den Krokodilen. Wissenschaftliche Zeitschrift der Ernst Moritz Arndt-Universität Greifswald 7:1-39.

Whitaker R, Basu D. 1983. The gharial (Gavialis gangeticus): A review. Journal of the Bombay Natural History Society 79:531-548.

Whitaker R, Whitaker Z. 1989. The ghara of the gharial. Hamadryad 14:2-3. 
522 Wilkinson PM, Rhodes WE. 1997. Growth rates of American alligators in coastal South 523 Carolina. Journal of Wildlife Management, 61:397-402.

524 Witmer LM. 1995a. The extant phylogenetic bracket and the importance of reconstructing soft 525 tissues in fossils. In: Thomason JJ ed. Functional morphology in vertebrate paleontology. 526 Cambridge, Cambridge University Press, 19-33

527 Witmer LM. 1995b. Homology of facial structures in extant archosaurs (birds and crocodilians),

528

529

530

531

532

533

534

535

536

537 538

541 Figure 2. Pterygoid bullae of Gavialis gangeticus (UF 118998) based on volume renders of

542 computed tomographic data of a dried skull. (A) Dorsolateral oblique view of the full skull 
543 showing the immature narial fossa and the pterygoid bulla, the latter being seen through the

544 orbit. (B-E) Dorsolateral oblique views of (B) the pterygoid bulla enlarged, (C) with the skull

545 roof digitally removed to reveal both bullae, and (D) with the dorsal portions of the bullae

546 removed to show the thin walls and the connection with the nasopharyngeal duct. (E) Close-up

547 ventral view of the pterygoid bullae projecting into the adductor muscle chamber. (F) Ventral

548 view of the full skull. All scale bars equal $5 \mathrm{~cm}$. A and F are at the same scale, as are B-F.

550 Figure 3. Pterygopalatine bullae of Alligator mississippiensis (OUVC 10615) based on volume

551 renders of computed tomographic data of a fleshy head. (A) Dorsolateral oblique view of the full

552 skull showing the pterygopalatine bulla as seen through the orbit. (B) Dorsolateral oblique view

553 of the pterygopalatine bulla enlarged with the skull roof digitally removed to reveal both bullae.

554 (C) Same presentation as in (B) but in dorsal view and enlarged. (D) Medial (internal) view of

555 the right side of a parasagittaly sectioned head, showing the pterygopalatine bulla emerging as a

556 dorsal dilation of the nasopharyngeal duct. (E) Ventral view of the full skull showing that the

557 pterygopalatine bulla is not visible in ventral view. All scale bars equal $5 \mathrm{~cm}$. A and E are at the

558 same scale, as are B and D, whereas C has its own scale.

559

560 Figure 4. Measurements used in the present study. Left inset details measurements from the

561 rostrum; right inset details measurement from the palate. See main text for the key to the

562 abbreviations. 
564 Figure 5. Distribution of narial fossa and pterygoid bullae presence/absence across gharial skulls

565 of different sizes (measured as MW). Insets at right illustrate the variable in question.

566

567 Figure 6. Reduced major axis regressions for nine of the continuous variables examined here. (A)

$568 \log$ BSL vs. $\log$ MW, (B) $\log$ OCW vs. $\log$ MW, (C) $\log$ SL_RTO vs. $\log$ MW, (D) $\log$ SMW

569 vs. $\log$ MW, (E) $\log$ PEMW vs. $\log$ MW, (F) $\log$ NMW vs. $\log$ MW, (G) $\log$ NML vs. $\log$ MW,

570 (H) $\log$ MWAO vs. $\log$ MW, (I) $\log$ IW vs. $\log$ MW. Males (possessing narial fossae) are

571 identified with blue triangles. Black dots represent osteologically immature individuals and/or

572 females.

573

574 Figure 7 . Residual variances ( $\pm 95 \%$ confidence intervals) for the nine continuous variables

575 examined. Numbers provided above each of the variables indicate sample size. 


\section{Figure 1}

Gharial snouts and the ghara

Figure 1. (A) bony snout of two male Gavialis gangeticus. The black arrows point to the fossae to which the ghara attaches. (B-F) various male $G$. gangeticus in the wild showing the range of size and morphology of the ghara. Image B provided by Nikhil Whitaker and images C-F provided by Jeffrey Lang, all used with permission.

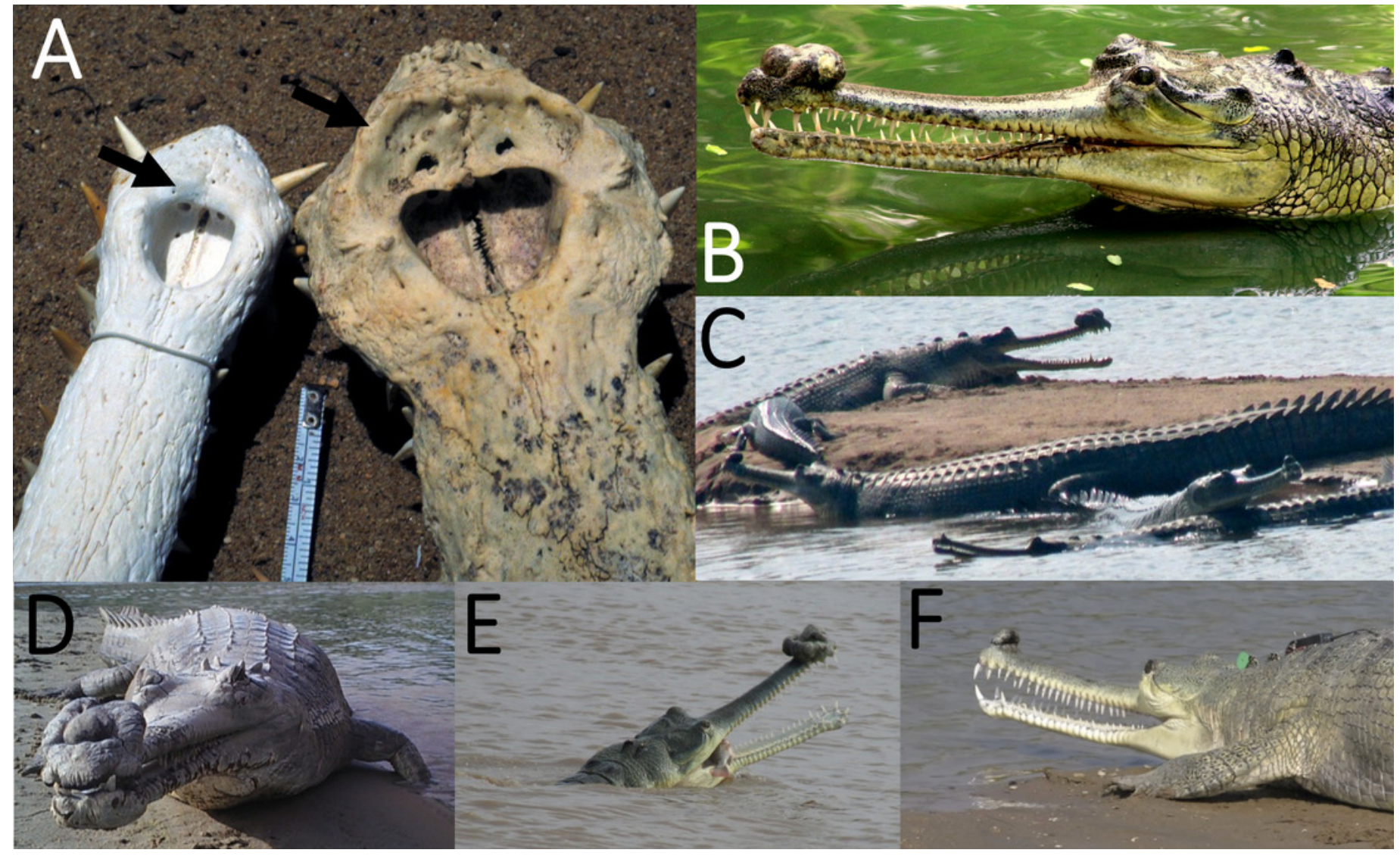




\section{Figure 2}

Pterygoid bullae of gharials

Pterygoid bullae of Gavialis gangeticus (UF 118998) based on volume renders of computed tomographic data of a dried skull. (A) Dorsolateral oblique view of the full skull showing the immature narial fossa and the pterygoid bulla, the latter being seen through the orbit. (B-E) Dorsolateral oblique views of (B) the pterygoid bulla enlarged, (C) with the skull roof digitally removed to reveal both bullae, and (D) with the dorsal portions of the bullae removed to show the thin walls and the connection with the nasopharyngeal duct. (E) Close-up ventral view of the pterygoid bullae projecting into the adductor muscle chamber. (F) Ventral view of the full skull. All scale bars equal $5 \mathrm{~cm}$. A and $\mathrm{F}$ are at the same scale, as are B-F. 
A Gavialis gangeticus UF 118998
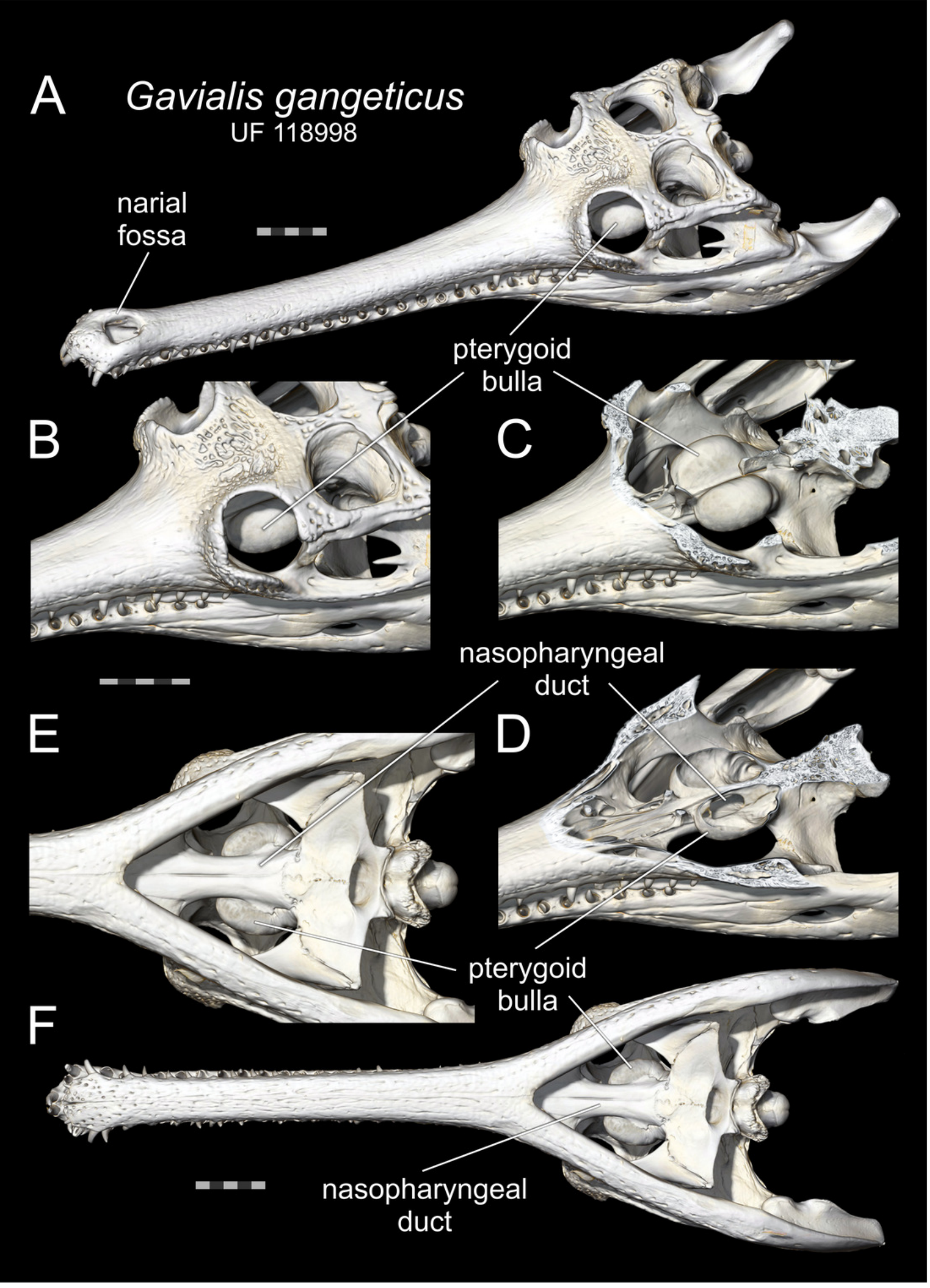


\section{Figure 3}

Pterygopalatine bullae of Alligator

Pterygopalatine bullae of Alligator mississippiensis (OUVC 10615) based on volume renders of computed tomographic data of a fleshy head. (A) Dorsolateral oblique view of the full skull showing the pterygopalatine bulla as seen through the orbit. (B) Dorsolateral oblique view of the pterygopalatine bulla enlarged with the skull roof digitally removed to reveal both bullae. (C) Same presentation as in (B) but in dorsal view and enlarged. (D) Medial (internal) view of the right side of a parasagittaly sectioned head, showing the pterygopalatine bulla emerging as a dorsal dilation of the nasopharyngeal duct. (E) Ventral view of the full skull showing that the pterygopalatine bulla is not visible in ventral view. All scale bars equal $5 \mathrm{~cm}$. A and $\mathrm{E}$ are at the same scale, as are $B$ and $D$, whereas $C$ has its own scale. 


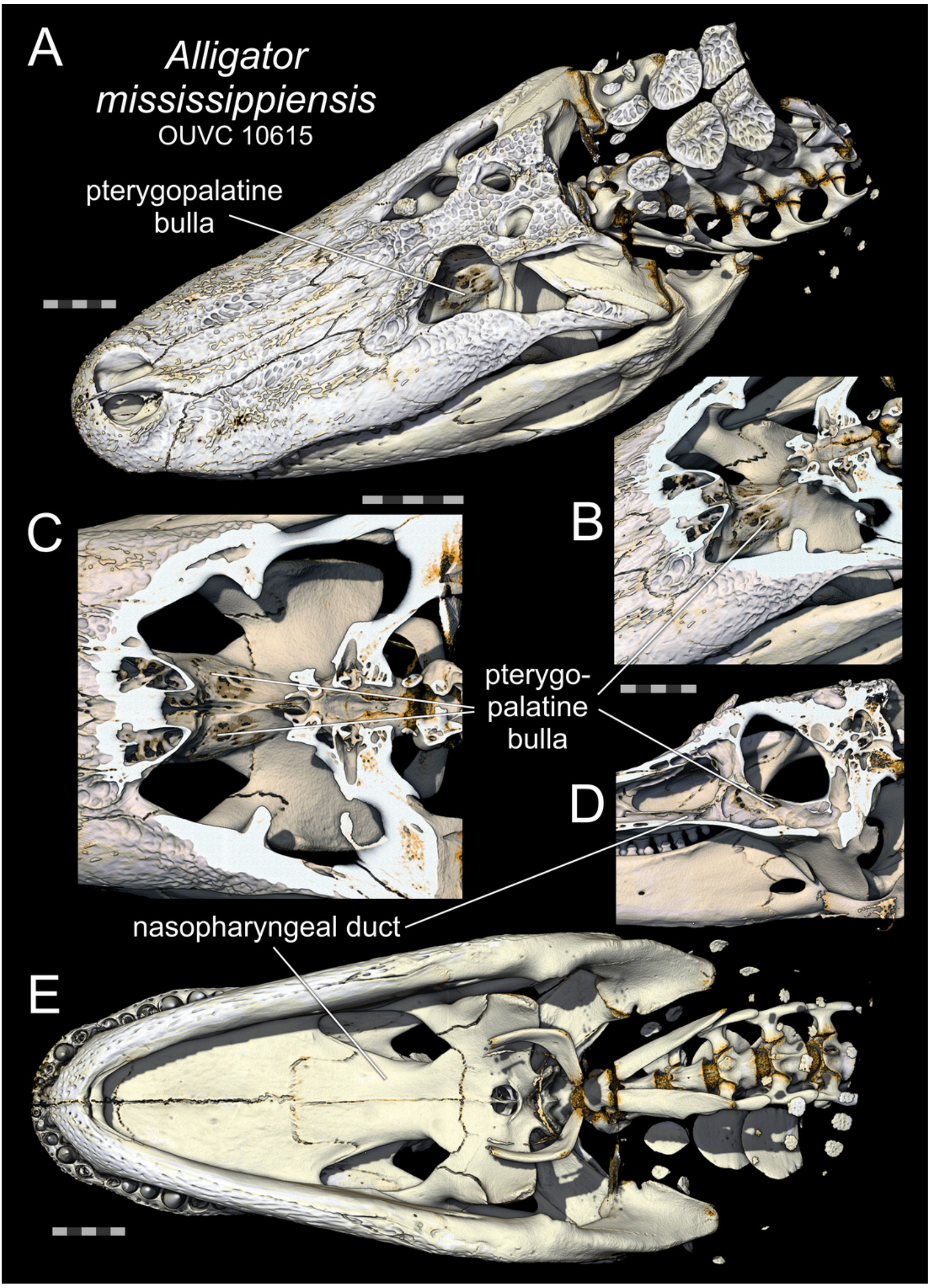


Figure 4

Measurements used in the present study

Measurements used in the present study. Left inset details measurements from the rostrum; right inset details measurement from the palate. See main text for the key to the abbreviations.

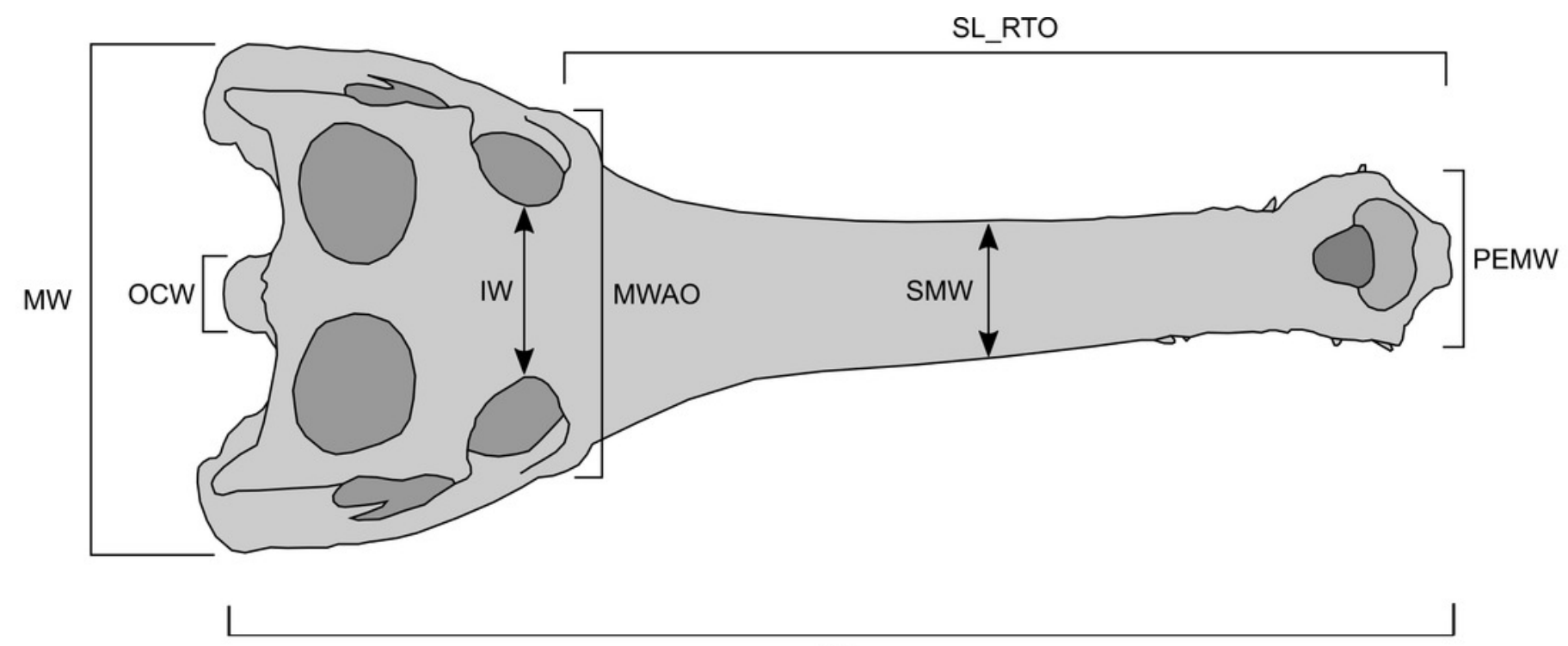

BSL
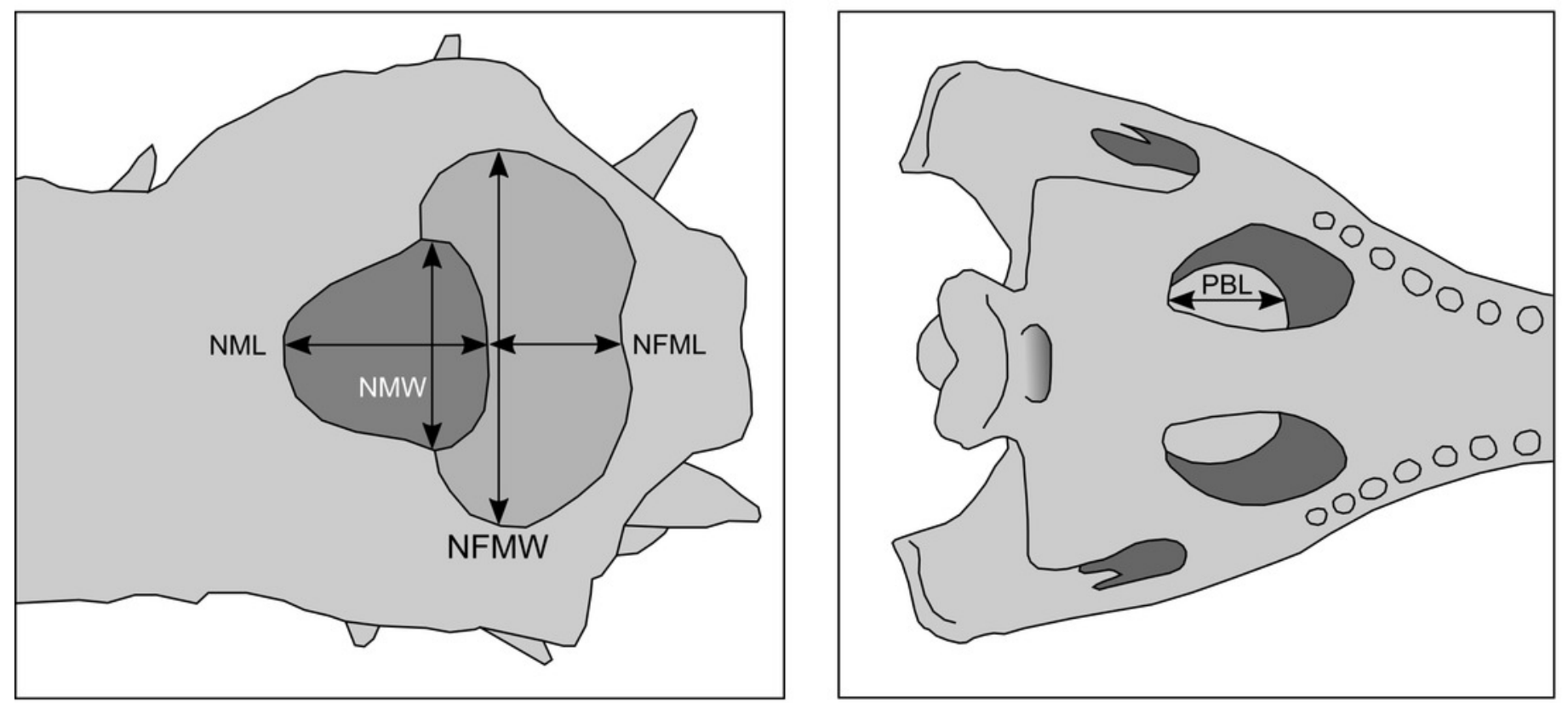
Figure 5

Gharial narial fossa and pterygoid bullae presence/absence

Distribution of narial fossa and pterygoid bullae presence/absence across gharial skulls of different sizes (measured as MW). Insets at right illustrate the variable in question.

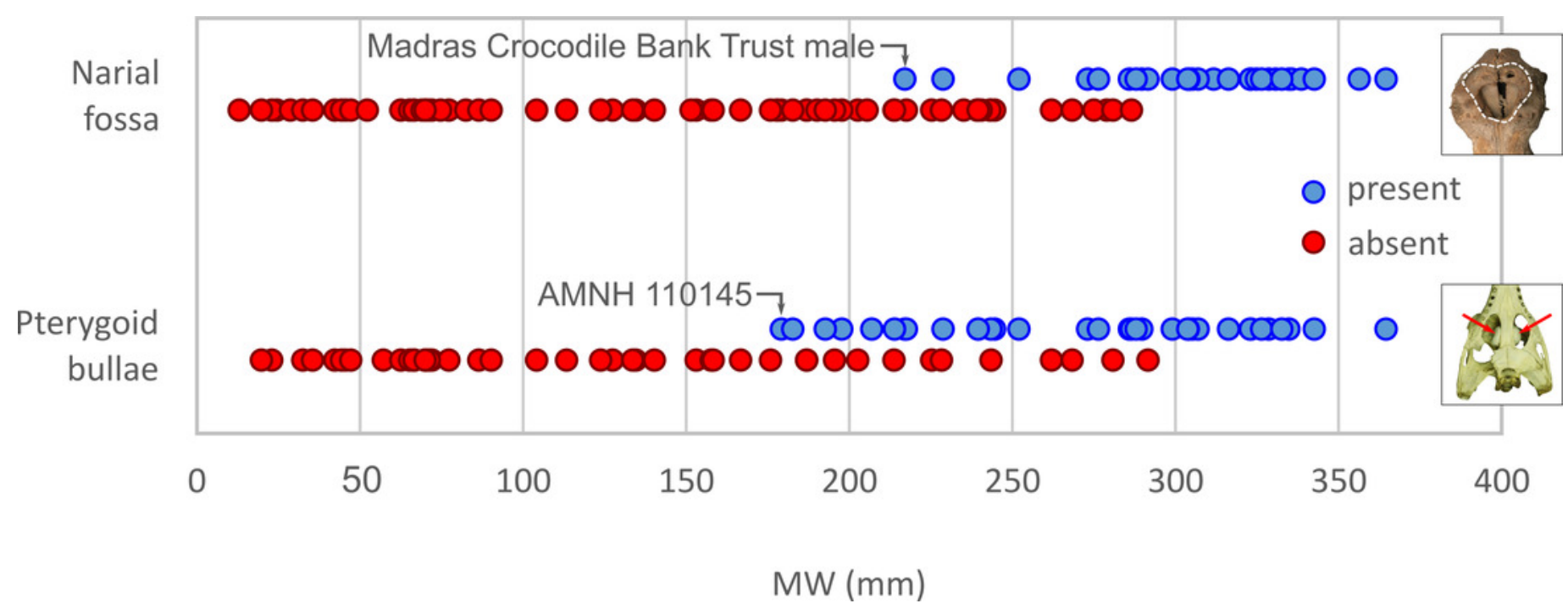


Figure 6

Reduced major axis regressions for nine of the assessed continuous variables

Reduced major axis regressions for nine of the continuous variables examined here. (A) log BSL vs. $\log M W,(B) \log O C W$ vs. $\log M W,(C) \log S L R R T O$ vs. $\log M W,(D) \log S M W$ vs. $\log M W$, (E) $\log P E M W$ vs. $\log M W,(F) \log N M W$ vs. $\log M W,(G) \log N M L$ vs. $\log M W,(H) \log M W A O$ vs. log MW, (I) log IW vs. log MW. Males (possessing narial fossae) are identified with blue triangles. Black dots represent osteologically immature individuals and/or females.
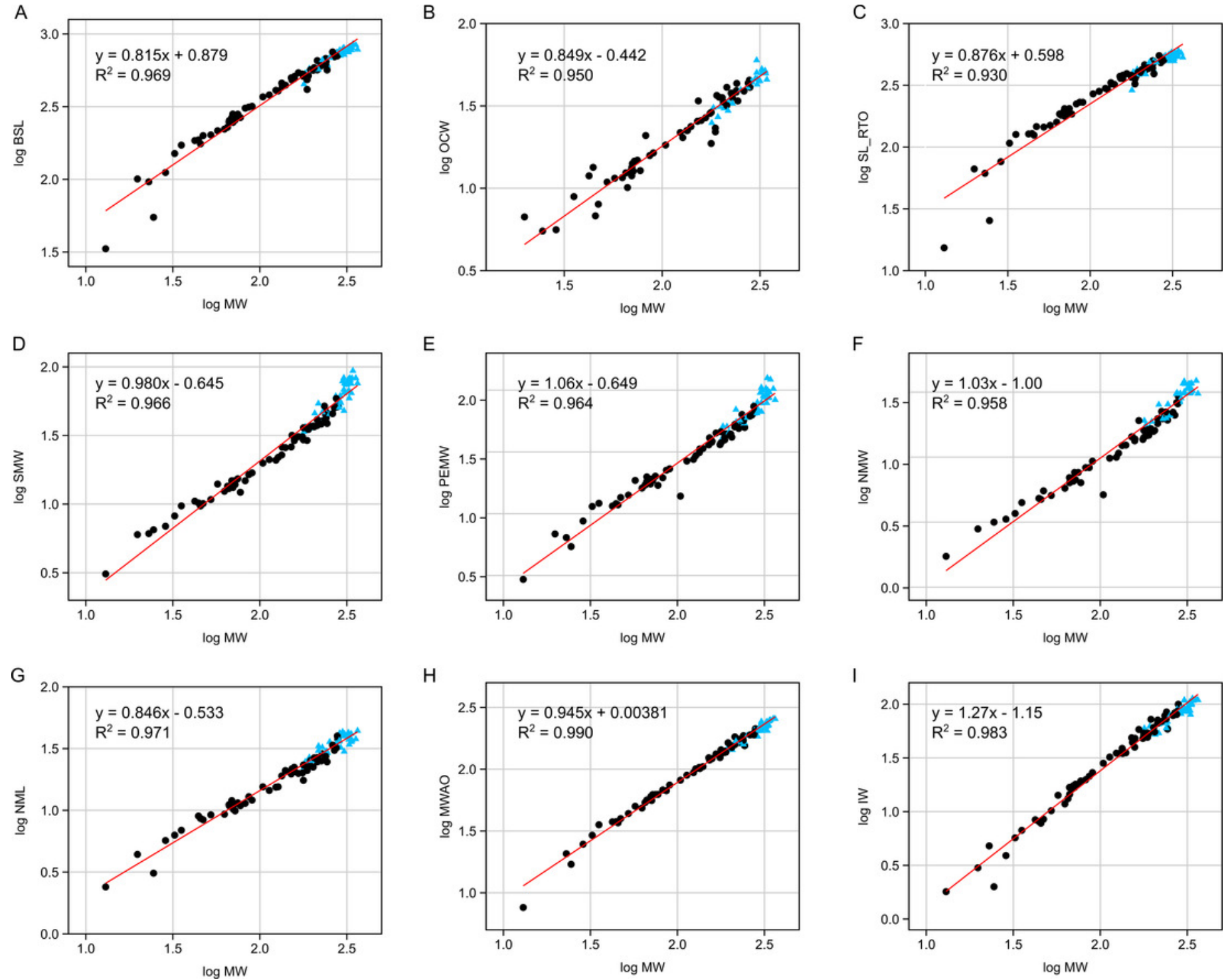
Figure 7

Residual variances for the nine continuous variables examined.

Residual variances ( $\pm 95 \%$ confidence intervals) for the nine continuous variables examined. Numbers provided above each of the variables indicate sample size.

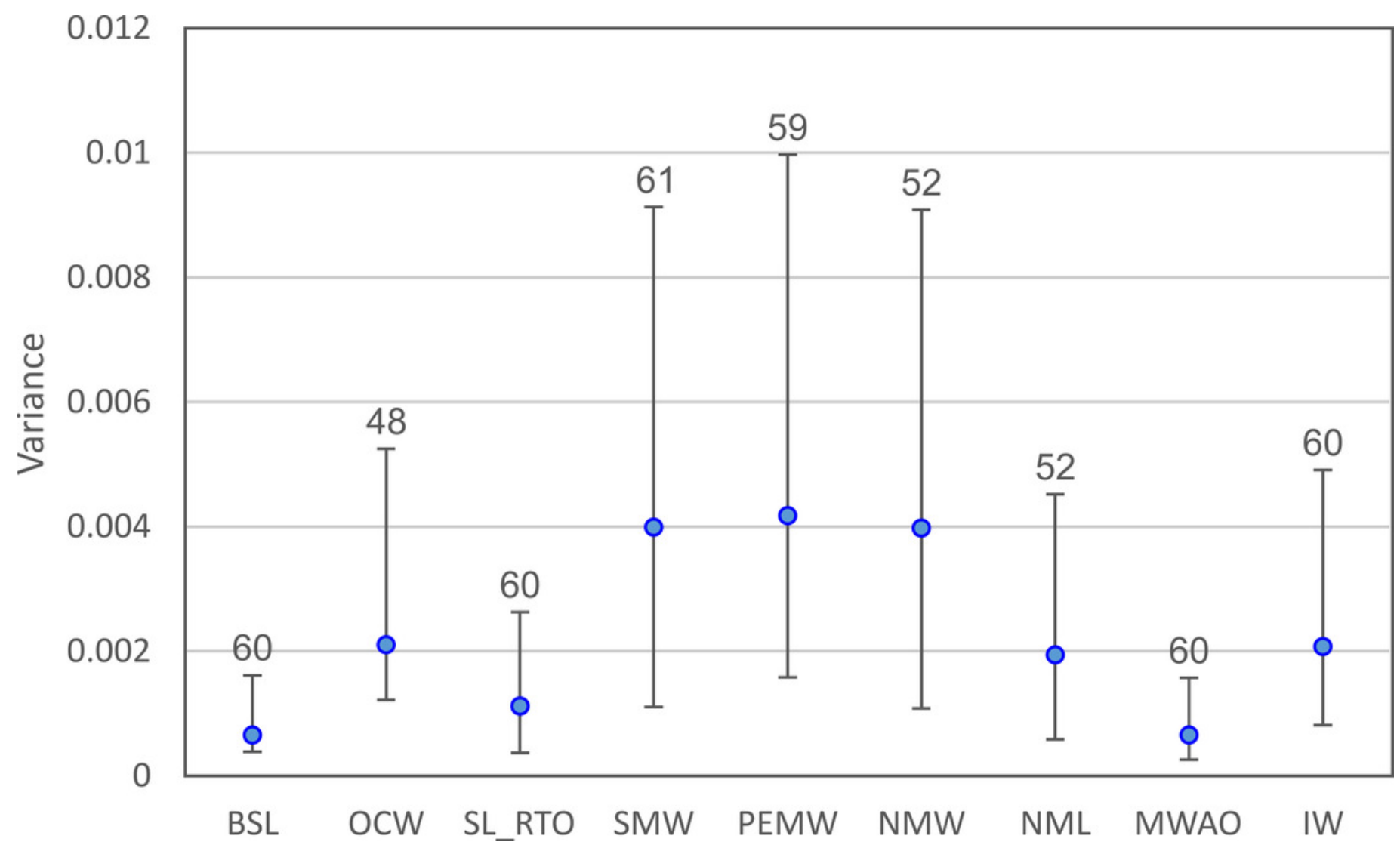

